\title{
Bonaparte vu par les mémorialistes français: une image à facettes.
}

Josiane Bourguet-Rouveyre

\section{(2) OpenEdition \\ 1 Journals}

Édition électronique

URL : https://journals.openedition.org/ahrf/286

DOI : $10.4000 / a h r f .286$

ISSN : 1952-403X

Éditeur :

Armand Colin, Société des études robespierristes

Édition imprimée

Date de publication : 1 décembre 1999

Pagination : 601-614

ISSN : 0003-4436

Référence électronique

Josiane Bourguet-Rouveyre, "Bonaparte vu par les mémorialistes français: une image à facettes. »,

Annales historiques de la Révolution française [En ligne], 318 | octobre-décembre 1999, mis en ligne le 16 avril 2004, consulté le 24 avril 2022. URL : http://journals.openedition.org/ahrf/286 ; DOI : https://

doi.org/10.4000/ahrf.286

Ce document a été généré automatiquement le 24 avril 2022.

Tous droits réservés 


\title{
Bonaparte vu par les mémorialistes français: une image à facettes.
}

\author{
Josiane Bourguet-Rouveyre
}

\section{RÉSUMÉS}

Il y a une légende du coup d'État de Brumaire durablement entretenue par les textes publiés par les compagnons de captivité de Napoléon à Sainte-Hélène. Selon elle, Bonaparte fut le sauveur appelé et porté au pouvoir par toute une nation que la déplorable faiblesse du Directoire avait excédée. Les témoignages des acteurs, spectateurs ou victimes de Brumaire racontent peut-être une autre histoire, moins mythique, plus humaine, et qui tend à démontrer que si le coup d'État n'était pas irrésistible, personne n'était vraiment prêt à lui résister. La fascination étrange qu'exerça Bonaparte, même sur ses adversaires, l'a emporté sur l'agacement suscité par les ambitions effrénées qu'on lui supposait déjà, gommant les maladresses du 19 brumaire et expliquant sans doute en grande partie les ralliements.

C'è una leggenda sul colpo di Stato di Brumaio permanentemente alimentata dai compagni di prigionia di Napoleone a sant'Elena. Secondo questa leggenda Bonaparte fu il salvatore chiamato e portato al potere da un'intera nazione esasperata dalla deprecabile debolezza del Direttorio. Le testimonianze degli attori, spettatori o vittime di Brumaio raccontano probabilmente un'altra storia, meno mitica, più umana, che tende a dimostrare che, se il colpo di Stato non era irrefrenabile, nessuno era realmente pronto a resistergli. La strana fascinazione esercitata da Bonaparte, persino sui suoi avversari, ha avuto la meglio sulla stizza suscitata dalle ambizioni sfrenate di cui era già sospettato, cancellando le goffaggini del 19 Brumaio e spiegando indubbiamente in gran parte le adesioni.

Bonaparte Portrayed by the French Memorialists: a MultifacetedView 
The coup d'État of Brumaire generated a legend long sustained by texts published by Napoleon's companions during his captivity at St. Helena. According to this legend, Bonaparte was the saviour called and carried to power by a whole nation exasperated by the deplorable weakness of the Directory. Evidence from the actors, spectators and victims of Brumaire tells another story, less mythical and more human, showing that, while the coup was not irresistible, no-one was really prepared to resist it. The strange fascination exerted by Bonaparte, even on his foes, tended to override the annoyance provoked by the boundiess ambition already ascribed to him, erasing the blunders of 19 Brumaire and explaining in large part why so many rallied to his banner.

Es gibt eine Legende des Staatsstreichs des 18. Brumaire, die durch die Veröffentlichungen der Begleiter Napoleons auf Insel Sankt-Helena lange unterhalten wurde : Bonaparte wäre der Retter gewesen, den die ganze Nation, die der jämmerlichen Schwäche des Direktoriums überdrüssig gewesen wäre, gerufen und an die Macht gebracht hätte. Die Teilnehmer, Zuschauer oder Opfer des Staatsstreichs erzählen vielleicht eine andere, weniger mythische, menschlichere Geschichte, die $\mathrm{zu}$ beweisen versucht, daß Bonaparte zwar nicht unwiderstehlich war, daß aber auch niemand bereit war, sich ihm zu widersetzen. Die seltsame Faszination, die der General selbst auf seine Gegner ausübte, hat schwerer gewogen als der Ärger, den sein schon erahnter grenzenloser Ehrgeiz erregt hatte. Sie hat die Mißgriffe des 19. Brumaire ausradiert und zweifellos die meisten Aussöhnungen erklärt. 